\title{
SUBJECTIVE NORM, ATTITUDES, TRUST, TERHADAP PURCHASE INTENTIONS PADA BUAH DAN MAKANAN ORGANIK
}

\author{
AILEN TANIA \\ DENNY SEPTA HARYANTI \\ Sekolah Tinggi Ilmu Ekonomi Trisakti, Jl. Kyai Tapa No. 20, Jakarta, Indonesia \\ dennysepta123@gmail.com
}

\begin{abstract}
The purpose of this research is to understand how information revealed on organic food label drive consumer trust and attitudes toward organic foods, which in turn together with subjective norm eventually influence subsequent purchase intentions of consumption on organic food in north Jakarta. This research used a quantitative method and use primary data such as respondent answer. Researcher used questionnaire to collect data from 100 respondent from Total Fresh Fruit supermarket at north Jakarta. In total, 100 valid questionnaires were obtained, yielding a response rate of 100 per cent. Researcher analysis the data using multiple linear regression with SPSS 25.0 for windows. The result showed attitudes, trust significantly effects purchase intentions of consumption on fruit and organic food, but the result with subjective norm is inversely proportional. Because most people buy organic food product at north Jakarta negatively not based by social pressure for a person to engage in or avoid a behavior effected by those people who important for them.
\end{abstract}

Keywords: Subjective norm, attitudes, trust, purchase intentions

Abstrak: Tujuan penelitian dilakukan adalah untuk memahami bagaimana informasi yang terungkap pada label makanan organik mendorong Trust dan Attitudes konsumen terhadap makanan organik, yang pada gilirannya bersama dengan Subjective Norm yang akhirnya mempengaruhi niat pembelian berikutnya kepada makanan organik di Jakarta Utara. Penelitian mengunakan metode kuantitatif dan menggunakan data primer seperti jawaban responden. Peneliti menggunakan kuesioner untuk mengumpulkan data dari 100 responden dari supermarket Total Buah Segar di Jakarta Utara. Secara total, 100 kuesioner yang valid diperoleh, menghasilkan tingkat respons 100 persen. Peneliti menganalisis data menggunakan regresi linier berganda dengan SPSS 25.0 untuk windows. Hasil penelitian menunjukan Attitudes, Trust berpengaruh terhadap nilai beli konsumsi pada buah dan makanan organik, tetapi hasil dengan Sujective Norm berbanding terbalik. Dikarenakan kebanyakan orang membeli produk makanan organik di Jakarta Utara dinilai secara negative tidak berdasarkan pada tekanan sosial bagi seseorang untuk terlibat atau menghindari prilaku yang di lakukan oleh orang - orang yang penting bagi mereka.

Kata kunci: Subjective norm, attitudes, trust, purchase intentions 


\section{PENDAHULUAN}

Seiring dengan perkembangan zaman yang semakin maju dan kemudahan masyarakat dalam mencari informasi, masyarakat luas semakin menyadari dampak daripada pentingnya kesehatan dan kelangsungan hidup di lingkungan sekitar. Banyak masyarakat yang menyadari buruknya dampak daripada kerusakan lingkungan yang ditimbulkan oleh bahan-bahan kimia atau bahan-bahan yang berbahaya untuk tubuh dan kelangsungan hidup di lingkungan termasuk makanan yang masuk ke dalam tubuh manusia.

Menurut penelitan Miles dan Frewer (2001), banyak krisis pasokan makanan yang menyebabkan kecemasan konsumen secara luas mengenai kualitas makanan yang dikonsumsi, diantaranya penyakit sapi gila, epidemi kaki-dan-mulut, dan skandal dioxins Belgia. Kecemasan yang terjadi meningkatkan kesadaran masyarakat akan makanan yang lebih aman untuk dikonsumsi dan mempertanyakan praktik pertanian moderen yang menggunakan bahan-bahan kimia yang berpotensi membahayakan konsumen seperti penggunaan pestisida dengan residu yang terserap dalam makanan. Dalam jangka panjang, residu yang terserap dan dikonsumsi oleh tubuh akan memberikan efek yang tidak diketahui untuk kesehatan.

Dari kasus diatas telah tercermin pada peningkatan permintaan produk makanan organik yang dianggap lebih ramah lingkungan dan lebih sehat dari makanan yang di tanam secara konvensional (Schifferstein dan Oude Ophuis 1998) (Williams dan Hammitt 2001). Makanan organik umumnya diproduksi tanpa menggunakan bahan kimia sintetis seperti pestisida dan pupuk yang secara definisi dapat dikatakan tidak dimodifikasi secara genetik.

Pasar makanan organik telah menjadi salah satu sektor yang tumbuh dengan cepat sebagai ekonomi bidang pertanian paling maju di seluruh dunia, terutama di Uni Eropa, meskipun tidak ada bukti yang jelas bahwa makanan organik dinilai lebih sehat daripada makanan konvensional, makanan organik dinilai mengandung lebih sedikit bahan adiktif berbahaya tetapi lebih primer (misalnya, vitamin C dan mineral) serta nutrisi sekunder (misalnya, Phytonutrients) dibandingkan dengan makanan konvensional. Dengan kata lain, makanan organik diasumsikan tidak membawa risiko keracunan makanan (Heaton 2001).

Definisi paling umum dari makanan yang diproduksi secara organik menekankan pada definisi diproduksi secara organik, pada teknologi atau praktik-praktik produksi serta prinsip-prinsip yang digunakan, dan/atau filosofi organik. Jadi, Sementara beberapa definisi menyoroti dimensi seperti sistem produksi biologis atau alami dan ramah lingkungan. Hal lainnya menekankan pada terbatasnya penggunaan bahan kimia buatan dalam produksi organik atau filosofi umumnya.

Karakteristik makanan organik yang penting bagi konsumen dikelompokkan menjadi atribut umum dan atribut spesifik komoditas. Atribut umum terkait dengan keamanan pangan dan kesehatan manusia, efek lingkungan serta aspek kesejahteraan hewan ternak, sementara atribut spesifik komoditas mencakup variabel seperti daya tarik visual, nilai gizi, rasa, kesegaran, dan sebagainya.

Dengan banyaknya fenomena yang terjadi pada pemilihan makanan organik. Soil Association (1994), Hutchins dan Greenhalgh (1997), Latacz-Lohmann dan Foster (1997) menyatakan bahwa Beberapa upaya telah dilakukan untuk menguji persepsi konsumen tentang makanan organik, faktor yang telah memfasilitasi atau mencegah pemilihan makanan organik, sikap konsumen serta alasan untuk membeli atau tidak membeli.

Beberapa penelitian telah mengindentifikasi motivasi konsumen dalam membeli makanan organik. Menurut penelitian Magnusson et al. (2003) Lockie et al. (2004) Padel dan Foster (2005) Honkanen, Verplanken, 
dan Olsen (2006) Aertsens et al. (2009), motivasi pembelian makanan organik adalah karena keperihatinan terhadap tingkat kesehatan, lingkungan, keamanan makanan, kesejahteraan binatang, rasa tangung jawab untuk melestarikan tingkat prekonomian lokal, gaya hidup, rasa nostalgia terhadap masa lalu, dan mengikuti gaya. Aertsens et al. (2009) menyebutkan bahwa nilai daripada motivasi pembelian makanan organik adalah bedasarkan daripada aspek keamanan, hedonisme, stimulasi, universalisme, pengarahan diri sendiri, kebijaksanaan, kenyamanan, dan kekuatan.

Sedangkan menurut penelitian Tregear, Dent, dan McGregor (1994), Chinnici, D'Amico, dan Pecorino (2002), Magnusson et al. (2003), Baker et al. (2004), dan Lockie et al. (2004), menyebutkan bahwa "Mereka telah beurusan dengan motivasi untuk membeli makanan organik, termasuk masalah kesehatan, masalah lingkungan, keamanan pangan. Variabel sensorik, masalah etika, atau struktur nilai".

Penelitian lain memandang perilaku pembelian makanan organik sebagai bagian perilaku pembelian 'hijau' yang lebih luas atau perilaku ramah lingkungan (Schlegelmilch et al., 1996). Banyak dari penelitian ini telah menggunakan Norm Activation Theory, atau versi modifikasi sebagai model untuk menjelaskan perilaku ramah lingkungan. Inti daripada teori ini adalah gagasan bahwa perilaku altruistik atau pro-lingkungan dipengaruhi oleh perasaan ataupun kewajiban moral untuk bertindak berdasarkan norma pribadi yang di-internalisasi seseorang, yang telah mengarah kepada Subjective Norm pada penelitian ini.

Subjective Norm menjadi aktif ketika seseorang menyadari konsekuensi yang berbahaya bagi orang lain yang disebabkan oleh keadaan lingkungan dan ketika orang tersebut memikul tanggung jawab kepadanya untuk mengubah kondisinya. Stern (2000). Selanjutnya, berdasarkan penelitian Teng dan
Wang (2015), mempelajari bahwa kriteria terpenting sebagai pendorong daripada pembelian makanan organik adalah pembuat produk, pemasok, ahli pemasaran, kebijakan pembuatan, dan tempat makan yang melakukan pengaitan pada strategi pasarnya. Sehingga menitik beratkan pada kepercayaan atau Trust.

Untuk melihat lebih jauh, ada penelitian yang cukup berfokus pada faktor-faktor yang dapat membantu konsumen menciptakan kepercayaan serta sikap positif terhadap makanan organik, atau mengeksplorasi bagaimana kombinasi faktor-faktor ini dapat meningkatkan konsumsi makanan organik. Para peneliti berpendapat bahwa kepercayaan adalah prasyarat penting untuk bisnis yang sukses karena konsumen dinilai akan ragu-ragu untuk melakukan pembelian kecuali mereka mempercayai penjual (D. J. Kim, Ferrin, dan Rao 2008).

Bredahl (2001), Cook et al. (2002), Conner et I. (2003) menjelaskan tentang Attitudes bahwa "Sikap dalam mengkonsumsi suatu produk telah ditemukan sebagai salah satu pemacu yang paling penting untuk memprediksi serta menjelaskan pilihan konsumen di seluruh produk serta layanan termasuk produk makanan". Penelitian sebelumnya telah meneliti hubungan antara sikap dalam mengkonsumsi dan pemilihan makanan organik yang akan mengarah pada Attitudes dalam penelitian ini (Squires, Juric, dan Bettina Cornwell 2001) (Lockie et al. 2004) (Dreezens et al. 2005).

Kepercayaan konsumen mungkin lebih penting dalam keputusan pembelian makanan organik daripada yang konvensional, dikarenakan kepercayaan dinilai sangat penting untuk prilaku pembelian makanan organik, sehingga penting untuk mengindentifikasi tingkat kepercayaan konsumen dalam konteks konsumsi makanan organik.

Selain itu, Attitudes dan Subjective Norm juga dinilai penting untuk menyadari bagaimana faktor pribadi dan sosial 
mempengaruhi perilaku individu (Ha 1998). Jika digabungkan, diperlukan untuk memasukan faktor-faktor kritis yang disebutkan di atas, termasuk tingkat dan variabel hasil daripada kepercayaan konsumen untuk mengembangkan model yang lebih komprehensif demi pemahaman yang lebih baik dari perilaku pemilihan makanan organik.

Dengan demikian, peneliti saat ini berusaha untuk menguji bagaimana mengungkapkan informasi pelabelan buah dan makanan organik serta pengetahuan buah dan makanan organik yang dirasakan akan mempengaruhi niat konsumen untuk membeli buah dan makanan organik melalui beberapa faktor seperti Subjective Norm, Attitudes, dan Trust kepada Purchase Intentions pada buah dan makanan organik yang bertempat pada toko Total Buah Segar Kelapa Gading 1 di jalan Boulevard Raya Blok L3 dan toko Total Buah Segar Kelapa Gading 2 di Boulevard block 19, Jakarta Utara.

Pemilihan toko Total Buah Segar sebagai lokasi daripada objek penelitian buah dan makanan organik ini didasari daripada fenomena toko Total Buah Segar yang terdaftar sebagai Top Brand pada Top Brand Award sebagai toko buah-buahan terbaik yang memiliki Top Brand Index Indonesia sebesar 37,3\% (teratas) pada Top Brand Index 2019 fase dua kategori toko buah-buahan. Serta toko Total Buah Segar yang menduduki peringkat pertama pada Top Brand Index fase dua, selama lima tahun terakhir secara berturut-turut dengan index 31,1\% (2015), 33,0\% (2016), 43,4\% (2017), 32,1\% (2018), 37,3\% (2019).

Dari duabelas gerai yang aktif, penelitian ini akan dilakukan pada gerai toko Total Buah Segar yang berada pada toko Total Buah Segar Kelapa Gading 1 di jalan Boulevard Raya Blok L3 dan toko Total Buah Segar Kelapa Gading 2 di Boulevard block 19, Jakarta Utara. dengan alasan bahwa toko Total Buah Segar Kelapa Gading 1, Jakarta Utara merupakan toko Total Buah Segar pertama yang berdiri sejak tahun 2003, serta toko Total Buah tersebut adalah Head office daripada seluruh toko Total Buah Segar yang tersebar di seluruh Indonesia. Sedangkan toko Total Buah Segar 2, merupakan anak cabang pertama daripada toko Total Buah Segar Kelapa Gading.

Menurut Chih-Ching Teng dan Yu - Mei Wang (2013), ada tiga hal yang menjadi faktor yang mempengaruhi purchase intentions pada buah dan makanan organik yaitu Subjective Norm, Attitudes, dan trust.

Bedasarkan faktor - faktor di atas akan sangat bermanfaat bagi setiap perusahaan khususnya toko Total Buah Segar untuk dapat menaikan Attitudes dan Trust pada prilaku pemasarannya guna meningkatkan purchase intentions.

\section{Purchase Intentions}

Kotler dan Keller (2012, 344) mendefinisikan purchase intentions sebagai niat pembelian adalah serangkaian tindakan yang mungkin terkait erat dengan sikap dan pertimbangan merek. Niat pembelian mengukur kencenderungan konsumen untuk membeli sebuah merek atau berpindah ke merek lain.

Menurut (Hong Youl Ha et al., 2014) niat pembelian adalah juga terkait dengan pembelian kembali atau kencenderungan untuk tetap dengan penyedia layanan.

\section{Subjective Norm}

Menurut (Ajzen 2001) Subjective Norm telah didefinisikan sebagai tekanan sosial yang dirasakan bagi seseorang untuk terlibat atau menghindari prilaku.

Subjective Norm mengacu kepada prilaku konsumer terhadap sesuatu tindakan maupun prilaku termasuk di dalam niat pembelian untuk membeli makanan organik. Hipotesis yang diajukan adalah:

$\mathrm{H}_{1}$ : Terdapat pengaruh Subjective Norm terhadap Purchase Intentions pada buah dan makan organik. 


\section{Attitudes}

Seperti yang telah di jelaskan oleh Kenneth.E.Clow, Donald Baack $(2018,79)$ sikap adalah posisi mental yang di ambil menuju suatu topik, seseorang, atau pristiwa yang mempengaruhi perasaan, persepsi, proses pembelajaran serta prilaku pemegang selanjutnya.

Melalui peninjauan deskripsi terkait, sikap terhadap atribut makanan organik (misalnya rasa, kesehatan, makanan, keamanan, masalah gizi, keramahan lingkungan, dan kesejahteraan hewan) telah diidentifikasi sebagai pendahulu utama yang memfasilitasi proses pengambilan keputusan konsumen dalam kaitannya dengan konsumsi makanan organic. Hipotesis yang diajukan:

$\mathrm{H}_{2}$ : Terdapat pengaruh Attitudes terhadap Purchase Intentions pada buah dan makan organik.

\section{Trust}

Kotler dan Keller (2012, 225) mendefinisikan Trust sebagai kesediaan perusahaan untuk bergantung pada mitra bisnis yang tergantung pada sejumlah faktor interpersonal dan antar organisasi seperti persepsi kompetensi, integritas, kejujuran, serta kebajikan perusahaan. Kepercayaan merupakan salah satu bentuk kepercayaan yang dirasakan konsumen terhadap suatu vendor.

$\mathrm{H}_{3}$ : Terdapat pengaruh Trust terhadap Purchase Intentions pada buah dan makan organik.

\section{METODE PENELITIAN}

Rancangan penelitian yang di gunakan yaitu penelitian deskriptif dan kasual. Karena penelitian ini bertujuan untuk mengetahui pengaruh Subjective Norm, Attitudes, dan Trust terhadap Purchase Intentions pada pembelian buah dan makanan organik pada Konsumer toko Total Buah Segar Kelapa Gading Jakarta Utara. Penelitian kasual menurut sugiyono (2016:65) merupakan hubungan yang bersifat sebab akibat. Jadi disini ada variabel independen (variable yang mempengaruhi) dan dependen (dipengaruhi). Dalam penelitian ini terdapat tiga variabel yang mempengaruhi yaitu Subjective Norm, Attitudes, dan Trust dan variabel yang dipengaruhi yaitu Purchase Intentions. Sedangkan penelitian deskriptif sering dirancang untuk mendapatkan data yang mengambarkan suatu karakteristik dari orang atau situasi.

Data yang di gunakan dalam penelitian ini adalah data primer dan data sekunder. Data primer menurut Sekaran dan Bougie $(2016,38)$ adalah data yang peneliti dapat pertama kali atau peneliti menjadi tangan pertama yang mendapat data tersebut untuk tujuan penelitian data primer merupakan data yang di dapatkan langsung oleh peneliti sebagai obyek penulisan. Data yang dikumpulkan dalam penelitian ini diperoleh dari responden dengan cara memberikan kuesioner. Data sekunder menurut Sekaran dan Bougie $(2016,37)$ adalah data yang telah di kumpulkan oleh orang lain dengan tujuan untuk penelitian. Data sekunder yang digunakan berasal dari jurnal, buku, website, serta jurnal yang berhubungan dengan penelitian.

Objek dari penelitian ini adalah buah dan makanan organik pada toko buah Total Buah Segar Kelapa Gading Jakarta Utara. Pengumpulan data akan dilakukan dengan penebaran kuesioner di toko Total Buah Segar Kelapa Gading Jakarta Utara pada tanggal 20 November 2019.

Teknik penentuan sampel menggunakan pendekatan Hair et al,. (2014, 100) yang menjelaskan penelitian sebaiknya tidak menggunakan sampel kurang dari 50, tetapi sebaiknya menggunakan 100 atau lebih besar. Jumlah sampel yang direncanakan untuk diambil oleh peneliti sebanyak 100 responden yang dimana jumlah sampel tersebut kurang lebih sama dengan ketentuan banyaknya 
sampel yang ditentukan oleh Hair et al. sebanyak minimal 100.

Metode pengambilan sampel yang digunakan dalam penelitian ini adalah non probability sampling dengan Teknik purposive sampling menurut Sekaran dan Bougie (2016, 247) Non-probability sampling merupakan Teknik pengambilan sampel yang dimana setiap anggota populasi tidak diberikan peluang yang sama untuk dipilih menjadi sampel.

Teknik penentuan sampel nonprobability yang digunakan dalam penelitian ini adalah purposive sampling menurut Sekaran dan bougie $(2016,72)$ adalah sampling dengan beberapa kireteria responden yang dapat memberikan suatu informasi, responden dipilih karena hanya dia yang dapat memberikan spesifik informasi yang dicari oleh peneliti.
Kireteria pengambilan sampel dalam penelitian ini adalah sebagai berikut:

1. Responden memiliki keinginan untuk melakukan pembelian makanan organik

2. Responden memiliki penghasilan

3. Responden sedang berada di toko Total

Buah Segar

4. Responden membeli sayur atau buah konvensional, biasa, curah atau tanpa merek dan membeli sayur atau buah organik dalam sekurang-kurangnya satu bulan terakhir

5. Pernah mendengar dan mengetahui mengenai buah atau sayur organik.

\section{HASIL PENELITIAN}

Hasil penelitian dari data yang didapatkan sebagai berikut:

Tabel 1 Karakteristik Responden Bedasarkan Jenis Kelamin

\begin{tabular}{ccccc}
\hline & & & Valid & cumulative \\
\hline Keterangan & Frequency & Percent & Percent & Percent \\
\hline Laki-laki & 54 & 54.0 & 54.0 & 54.0 \\
Wanita & 46 & 46.0 & 46.0 & 100.0 \\
Total & 100 & 100.0 & 100.0 & \\
\hline
\end{tabular}

Sumber: hasil output statistik

Tabel 2 Karakteristik Responden Bedasarkan Usia

\begin{tabular}{ccccc}
\hline Keterangan & Frequency & Percent & $\begin{array}{c}\text { Valid } \\
\text { Percent }\end{array}$ & $\begin{array}{c}\text { Cumulative } \\
\text { Percent }\end{array}$ \\
\hline$<21$ tahun & 5 & 5.0 & 5.0 & 5.0 \\
$21-30$ tahun & 41 & 41.0 & 41.0 & 46.0 \\
$26-30$ tahun & 26 & 26.0 & 26.0 & 72.0 \\
$31-35$ tahun & 15 & 15.0 & 15.0 & 87.0 \\
$36-40$ tahun & 13 & 13.0 & 13.0 & 100.0 \\
Total & 100 & 100.0 & 100.0 & \\
\hline
\end{tabular}

Sumber: hasil output statistik 
Tabel 3 Karakteristik Responden Bedasarkan Pendidikan Terakhir

\begin{tabular}{ccccc}
\hline Keterangan & Frequency & Percent & $\begin{array}{c}\text { Valid } \\
\text { percent }\end{array}$ & $\begin{array}{c}\text { Cumulative } \\
\text { percent }\end{array}$ \\
\hline SMP & 2 & 2.0 & 2.0 & 2.0 \\
SMA & 4 & 4.0 & 4.0 & 6.0 \\
Diploma / & 50 & 50.0 & 50.0 & 56.0 \\
$\begin{array}{c}\text { Sarjana } \\
\text { Paska }\end{array}$ & 28 & 28.0 & 28.0 & 84.0 \\
$\begin{array}{c}\text { Sarjana } \\
\text { (S-2) }\end{array}$ & & & & \\
$<$ Paska & 16 & 16.0 & 16.0 & 100.0 \\
$\begin{array}{c}\text { Sarjana } \\
\text { (S -2) }\end{array}$ & & & & \\
Total & 100 & 100.0 & 100.0 & \\
\hline Sutal & & & &
\end{tabular}

Sumber: hasil output statistik

Tabel 4 Karakteristik Responden Bedasarkan Pekerjaan

\begin{tabular}{ccccc}
\hline Keterangan & Frequency & Percent & $\begin{array}{c}\text { Valid } \\
\text { percent }\end{array}$ & Cumulative \\
\hline $\begin{array}{c}\text { Pelajar / } \\
\text { Mahasiswa }\end{array}$ & 5 & 5.0 & 5.0 & 5.0 \\
$\begin{array}{c}\text { Pegawai } \\
\quad \text { Negri }\end{array}$ & 24 & 24.0 & 24.0 & 29.0 \\
$\begin{array}{c}\text { Pegawai } \\
\text { Swasta }\end{array}$ & 37 & 37.0 & 37.0 & 66.0 \\
$\begin{array}{c}\text { Wiraswasta } \\
\text { Total }\end{array}$ & 34 & 34.0 & 34.0 & 100.0 \\
\hline
\end{tabular}

Sumber: hasil output statistik

Tabel 5 Karakteristik Responden Bedasarkan Pendapatan per Bulan

\begin{tabular}{ccccc}
\hline Keterangan & Frequency & Percent & $\begin{array}{c}\text { Valid } \\
\text { Percent }\end{array}$ & $\begin{array}{c}\text { Cumulative } \\
\text { Percent }\end{array}$ \\
\hline < IDR 3.900.000,- & 6 & 6.0 & 6.0 & 6.0 \\
IDR 3.900.000,- s/d IDR & 15 & 15.0 & 15.0 & 21.0 \\
$\quad$ 5.000.000,- & & & & \\
IDR 5.000.000,- s/d IDR & 46 & 46.0 & 46.0 & 67.0 \\
$\quad$ 8.000.000,- & & & & \\
> IDR 8.000.000,- & 33 & 33.0 & 33.0 & 100.0 \\
$\quad$ Total & 100 & 100.0 & 100.0 & \\
\hline
\end{tabular}

Sumber: hasil output statistik 
Tabel 6 Hasil Uji Validitas

\begin{tabular}{ccccc}
\hline Variable & Indikator & R-hitung & R-tabel & Hasil \\
\hline \multirow{5}{*}{ Subjective Norm } & SN1 & 0,446 & 0,1946 & Valid \\
& SN2 & 0.434 & 0,1946 & Valid \\
& SN3 & 0,463 & 0,1946 & Valid \\
& SN4 & 0,589 & 0,1946 & Valid \\
& A1 & 0,605 & 0,1946 & Valid \\
Attitudes & A2 & 0,627 & 0,1946 & Valid \\
& A3 & 0,554 & 0,1946 & Valid \\
& A4 & 0,417 & 0,1946 & Valid \\
& A5 & 0,497 & 0,1946 & Valid \\
& A6 & 0,386 & 0,1946 & Valid \\
& A7 & 0,391 & 0,1946 & Valid \\
& T1 & 0,517 & 0,1946 & Valid \\
Trust & T2 & 0,640 & 0,1946 & Valid \\
& T3 & 0,702 & 0,1946 & Valid \\
& T4 & 0,674 & 0,1946 & Valid \\
& PI1 & 0,563 & 0,1946 & Valid \\
& PI2 & 0,757 & 0,1946 & Valid \\
Purchase Intentions & PI3 & 0,732 & 0,1946 & Valid \\
\hline
\end{tabular}

Sumber: hasil output statistik

Bedasarkan table di atas dapat disimpulkan bahwa variable dependen (Purchase Intentions) dan variable independen (Subjective Norm, Attitudes, Trust) memiliki nilai r hitung positif dan memiliki jumlah yang lebih besar jika dibandingkan dengan nilai $r$ table. Oleh karena itu semua pertanyaan kuesioner ini valid.

Tabel 7 Hasil Uji Reabilitas

\begin{tabular}{ccc}
\hline Variabel & Cronbach Alpha & Hasil \\
\hline Subjective Norm (X1) & 0,695 & Reliable \\
Attitudes (X2) & 0,767 & Reliable \\
Trust (X3) & 0,812 & Reliable \\
Purchase Intentions (Y) & 0,818 & Reliable \\
\hline Sumber: Hasil Output Statistik & &
\end{tabular}

Tabel 8 Hasil Koefisien Determinasi (R Square) dan (R)

\begin{tabular}{cccc}
\hline$R$ & R-Square & $\begin{array}{c}\text { Ajusted } R \\
\text { Square }\end{array}$ & $\begin{array}{c}\text { Std. Error of } \\
\text { the Estimate }\end{array}$ \\
\hline 0,592 & 0,350 & 0,330 & 1,60156 \\
\hline \multicolumn{2}{l}{ Sumber: Hasil output Statistik } & &
\end{tabular}


Pada tabel di atas dapat dilihat nilai koefisien kolerasi $(R)$ sebesar 0,592 yang berarti Subjective Norm, Attitudes, Trust, dan Purchase Intentions memiliki hubungan yang sedang karena terletak pada 0,40 - 0,599. Koefisien determinasi ( $R$ Square) menunjukan angka 0,350 yang dimana memiliki arti bahwa sebesar
35 persen variasi Purchase Intentions ( $Y$ ) dapat dijelaskan oleh variasi variabel Subjective Norm (X1), Attitudes (X2), dan Trust (X3). Sisanya sebesar 65 persen dijelaskan oleh variasi variabel lain yang tidak terdapat dalam penelitian ini.

Tabel 9 Hasil Regresi Berganda

\begin{tabular}{cccccc}
\hline Variabel & B & Std. Error & Beta & T & Sig. \\
\hline (constant) & $-0,266$ & 1,668 & & $-0,159$ & 0,874 \\
X1 & 0,144 & 0,083 & 0,123 & 1,360 & 0,177 \\
X2 & 0,220 & 0,0506 & 0,373 & 3,902 & 0,000 \\
X3 & 0,236 & 0,086 & 0,253 & 2,746 & 0,007 \\
\hline
\end{tabular}

Sumber: Hasil Output Statistik

Bedasarkan table di atas mengenai hasil uji $F$, menunjukan bahwa persamaan yang digunakan dalam penelitian termasuk kedalam kategori fit atau cocok dan diperoleh $\mathrm{F}$ hitung sebesar 17,251. Dengan menentukan drajad kebebasan $\mathrm{df}=\mathrm{n}-\mathrm{k}-1$ maka dapat disimpulkan bahwa $\mathrm{df}=100-3-1$ sehingga mendapatkan hasil $\mathrm{df}=96$. Dan jika kita melihat table $F$ dengan df 96 dan varian independen sebanyak 3 kita dapat menemukan nilai $F$ table yaitu 2,70 . Nilai $F$ hitung lebih besar daripada $F$ table $(17,251>2,70)$ dan memiliki tingkat signifikansi $0,000<0,050$, maka model regresi baik untuk memprediksi variabel dependen dan layak untuk dijadikan acuan untuk pengambilan keputusan.

Nilai signifikansi untuk Subjective norm (X1) adalah sebesar 0,117 yang dimana memikiki nilai lebih besar dari 0,05 yang memiliki kesimpulan bahwa $\mathrm{H}_{1}$ tidak diterima, artinya tidak terdapat pengaruh Subjective norm terhadap Purchase Intentions pada buah dan makanan organik di toko Total Buah Kelapa Gading, Jakarta Utara. Nilai signifikansi untuk Attitudes (X2) adalah sebesar 0,000 yang dimana memikiki nilai lebih kecil dari 0,05 yang memiliki kesimpulan bahwa $\mathrm{H}_{2}$ diterima, artinya terdapat pengaruh Attitudes terhadap Purchase Intentions pada buah dan makanan organik di toko Total Buah Kelapa Gading, Jakarta Utara. Nilai signifikansi untuk Trust (X3) adalah sebesar 0,007 yang dimana memikiki nilai lebih kecil dari 0,05 yang memiliki kesimpulan bahwa $\mathrm{H}_{3}$ diterima, artinya terdapat pengaruh Trust terhadap Purchase Intentions pada buah dan makanan organik di toko Total Buah Kelapa Gading, Jakarta Utara.

\section{PENUTUP}

Bedasarkan dari hasil penelitian yang telah diteliti dan juga pembahasan yang sudah di uraikan, maka peneliti menarik kesimpulan bahwa tidak adanya pengaruh Subjective Norm terhadap Purchase Intentions pada buah dan makanan organic, adanya pengaruh Attitudes terhadap Purchase Intentions pada buah dan makanan organik, dan adanya pengaruh Trust terhadap Purchase Intentions pada buah dan makanan organik di toko Total Buah Kelapa Gading, Jakarta Utara. 


\section{REFERENCES:}

Aertsens, Joris, Wim Verbeke, Koen Mondelaers, dan Guido van Huylenbroeck. 2009. Personal determinants of organic food consumption: A review. British Food Journal. Vol. 111. https://doi.org/10.1108/00070700910992961.

Ajzen, I. 2001. "Nature and operation of attitudes." Annual Review of Psychology 52: 27-58.

Ajzen, I., dan M. Fishbein. 1980. Understanding attitudes and predicting social behaviour. Englewood Hills: Prentice-Hall.

Alvesleben, R. Von. 1997. "Consumer behavior." In, diedit oleh D.I. Padberg, C. Ritson, dan L.M. Albisu, 209-44. New York: Agro-Food Marketing, CAB International.

Baker, S., K.E. Thompson, J. Engelken, dan K. Huntley. 2004. "Mapping the values driving organic food choice: Germany vs the UK." European Journal of Marketing 38 (8): 995-1012.

Bredahl, L. 2001. "Determinants of consumer attitudes and purchase intentions with regard to genetically modified foods - Results of a cross-national survey." Journal of Consumer Policy 24: 23-61.

Chen, Mei Fang. 2007. "Consumer attitudes and purchase intentions in relation to organic foods in Taiwan: Moderating effects of food-related personality traits." Food Quality and Preference 18 (7): 1008-21. https://doi.org/10.1016/j.foodqual.2007.04.004.

Chinnici, G., M. D'Amico, dan B. Pecorino. 2002. "A multivariate statistical analysis on the consumers of organic products." British Food Journal 104 (3/4/5): 187-99.

Crosby, L. A., K. R. Evans, dan D. Cowles. 1990. "Relationship quality in services selling: an interpersonal influence perspective." Journal of Marketing 54 (3): 68-81.

Davies, Anne, Albert J. Titterington, dan Clive Cochrane. 1995. "Who buys organic food?" British Food Journal 97 (10): 17-23. https://doi.org/10.1108/00070709510104303.

Dreezens, E., C. Martijn, P. Tenbult, G. Kok, dan N. K. de Vries. 2005. "Food and values: an examination of values underlying attitudes toward genetically modified- and organically grown food products." Appetite 44 (1): 115-22.

Eagly, A. H., dan S. Chaiken. 1993. The psychology of attitudes. Fort Worth. TX: Harcourt Brace Jovanovich College Publishers.

Garbarino, E., dan M.S. Johnson. 1999. "The different roles of satisfaction, trust, and commitment in customer relationships." Journal of Marketing 63 (2): 70-87.

Gefen, D. 2004. "What makes an ERP implementation relationship worthwhile: linking trust mechanisms and ERP usefulness." Journal of Management Information Systems 21 (1): 263-88.

Ghozali, Imam. 2018. Aplikasi Analisis Multivariate dengan Program IBM SPSS 25. 9 ed. Semarang: Badan Penerbit Universitas Diponegoro.

Gifford, Katie, dan John C. Bernard. 2006. "Influencing consumer purchase likelihood of organic food." International Journal of Consumer Studies 30 (2): 155-63. https://doi.org/10.1111/j.1470-6431.2005.00472.x.

Grankvist, Gunne, dan Anders Biel. 2007. "Predictors of purchase of eco-labelled food products: A panel study." Food Quality and Preference 18 (4): 701-8. https://doi.org/10.1016/j.foodqual.2006.11.002.

Grunert, C.S., dan J.H. Juhl. 1995. "Values, environmental attitudes and buying of organic foods." Journal of Economic Psychology 6: 39-62.

Ha, C. L. 1998. "The theory of reasoned action applied to brand loyalty." Journal of Product and Brand Management 7 (1): 51-61.

Hair, Joseph F., William C. Black, Barry J. Babin, dan Rolph E. Anderson. 2014. Multivariate Data Analysis. United Kingdom: Pearson Education Limited.

Hart, P., dan C. Saunders. 1997. "Power and trust: critical factors in the adoption and use of electronic data interchange." Organization Science 8 (1): 23-42.

Heaton, S. 2001. Organic farming, food quality and human health: A review of the evidence. Bristol: Soil Association.

Hill, H., dan F. Lynchehaun. 2002. "Organic milk: attitudes and consumption patterns." British Food Journal 104 
(7): $526-42$.

Hjelmar, Ulf. 2011. "Consumers' purchase of organic food products. A matter of convenience and reflexive practices." Appetite 56 (2): 336-44. https://doi.org/10.1016/j.appet.2010.12.019.

Honkanen, Pirjo, Bas Verplanken, dan Svein Ottar Olsen. 2006. "Ethical values and motives driving organic food choice." Journal of Consumer Behaviour 5 (5): 420-30. https://doi.org/10.1002/cb.190.

Hughner, Renée Shaw, Pierre McDonagh, Andrea Prothero, Clifford J. Shultz, dan Julie Stanton. 2007. "Who are organic food consumers? A compilation and review of why people purchase organic food." Journal of Consumer Behaviour 6 (2-3): 94-110. https://doi.org/10.1002/cb.210.

Hutchins, R.K., dan L.A. Greenhalgh. 1997. "Organic confusion: sustaining competitive advantage." British Food Journal 99 (9): 336-38.

Janssen, M., dan U. Hamm. 2012. "Product labelling in the market for organic food: consumer preferences and willingness-to-pay for different organic certification logos." Food Quality and Preference 25 (1): 9-22.

Kim, D. J., D. L. Ferrin, dan H. R. Rao. 2008. "A trust-based consumer decision-making model in electronic commerce: the role of trust, perceived risk, and their antecedents." Decision Support Systems 44 (2): 54464.

Kim, H.W., H.C. Chan, dan Y.P Chan. 2007. "A balanced thinking-feelings model of information systems continuance." International Journal of Human-Computer Studies 65 (6): 511-25.

Kotler, Philip, dan Kevin Lane Keller. 2012. Marketing management. 14 ed. England: Pearson Education Ltd. 2016. Marketing management. 15 ed. England: Pearson Education Ltd.

Kramer, R.M. 1999. "Trust and distrust in organizations: emerging perspectives, enduring questions." Annual Review of Psychology 50 (1): 569-98.

Latacz-Lohmann, U., dan C. Foster. 1997. "From niche to mainstream. Strategies for

marketing organic food in Germany and the UK." British food journal 99 (8/9): 275-82.

Lockie, S., K. Lyons, G. Lawrence, dan J. Grice. 2004. "Choosing organics: a path analysis of factors underlying the selection of organic food among Australian consumers." Appetite 43 (2): 135-46.

Magnusson, M. K., Anne Arvola, Ulla-Kaisa Koivisto Hursti, dan Lars Aberg. 2001. "Attitudes towards organic foods among Swedish consumers." British Food Journal 103: 209-26.

Magnusson, M.K., A. Arvola, U. Koivisto Hursti, L. Aberg, dan P.O. Sjo"den. 2003. "Choice of organic foods is related to perceived consequences for human health and to environmentally friendly behaviour." Appetite 40 (2): 109-17.

Makatouni, Aikaterini. 1999. "The consumer message: what motivates parents to buy organic food in the UK?" In Communication the Quality of Organic Food. Florence: IFOAM.

Miles, Susan, dan Lynn J. Frewer. 2001. "Investigating specific concerns about different food hazards." Food Quality and Preference 12 (1): 47-61. https://doi.org/10.1016/S0950-3293(00)00029-X.

Morgan, R. M., dan S. D. Hunt. 1994. "The commitment-trust theory of relationship marketing." Journal of Marketing $58(3): 20-38$.

Morris, L. 1996. "The Ethical Consumer: A New Force in the Food Sector?"

Mowen, J. 1993. Consumer behaviour. New York: Macmillan Publishing.

Padel, Susanne, dan Carolyn Foster. 2005. "Exploring the gap between attitudes and behaviour: Understanding why consumers buy or do not buy organic food." British Food Journal 107 (8): 606-25. https://doi.org/10.1108/00070700510611002.

Poulston, J., dan A. Y. K. Yiu. 2011. "Profit or principles: why do restaurants serve organic food?" International Journal of Hospitality Management 30 (1): 184-91.

Saba, A., dan F. Messina. 2003. "Attitudes towards organic foods and risk/benefit perception associated with pesticides." Food Quality and Preference 14: 637-45.

Schifferstein, H.N.J., dan P.A.M. Oude Ophuis. 1998. "Health-related determinants of organic food consumption in The Netherlands." Food Quality and Preference 9: 119-33.

Schwartz, Shalom H. 1977. "Normative influences on altruism." Advances in Experimental Social Psychology 10 (C): 221-79. https://doi.org/10.1016/S0065-2601(08)60358-5. 
1992. "Universals in the content and structure of values: theoretical advances and empirical tests in 20 countries." Advances in Experimental Social Psychology 25 (1): 65.

Sekaran, Uma, dan Roger Bougie. 2016. Research Method for Business A Skill-Building Approach. 7 ed. UK: John Wiley \& Sons Ltd.

Soil Association. 1994. "Soil Association Organic Food and Farming Report." Bristol.

_. 2000. "Soil Association Organic Food and Farming Report." Bristol. 2002. "Soil Association Organic Food and Farming Report." Bristol.

Sparks, P., dan R. Shepherd. 1992. "Self-identity and the theory of planned behaviour: assessing the role of identification with 'green consumerism." Social Psychology Quarterly 55 (4): 388-99.

Squires, Lisa, Biljana Juric, dan T. Bettina Cornwell. 2001. "Level of market development and intensity of organic food consumption: cross-cultural study of Danish and New Zealand consumers." Journal of Consumer Marketing 18 (5): 392-409. https://doi.org/10.1108/07363760110398754.

Stern, P.C. 2000. "Toward a coherent theory of environmentally significant behaviour." Journal of Social Issues 56 (3): 407-24.

Sugiyono. 2016. Metode Penelitian Kuantitatif, Kualitatif dan R\&D. Bandung: PT Alfabet.

Suh, B., dan I. Han. 2003. "The impact of customer trust and perception of security control on the acceptance of electronic commerce." International Journal of Electronic Commerce 7 (3): 135-61.

Teng, Chih Ching, dan Yu Mei Wang. 2015. "Decisional factors driving organic food consumption: Generation of consumer purchase intentions." British Food Journal 117 (3): 1066-81. https://doi.org/10.1108/BFJ-122013-0361.

Totalbuah.id. 2018. "About Total Buah." 2018. http://totalbuah.id/about/.

Tregear, A., J.B. Dent, dan M.J. McGregor. 1994. "The demand for organically grown produce." British Food Journal 95 (4): 21-25.

Williams, Pamela R.D., dan James K. Hammitt. 2001. "Perceived risks of conventional and organic produce: Pesticides, pathogens, and natural toxins." Risk Analysis 21 (2): 319-30. https://doi.org/10.1111/02724332.212114.

Wu, I. L., dan J. L. Chen. 2005. "An extension of trust and TAM model with TPB in the initial adoption of on-line tax: an empirical study." International Journal of Human-Computer Studies 62 (6): 784-808. 